\title{
Zygomatic Air Cell Defect: Prevalence and Characteristics in Dental Outpatient Population
}

Rohit Gadda, Neha Anil Patil, Rohini Salvi

\section{ABSTRACT}

Aim: To determine the prevalence, radiographic appearance and characteristics of patients with zygomatic air cell defect (ZACD).

Materials and methods: Routine panoramic radiographs of 400 patients who were visited the dental outpatient of our institute were examined retrospectively.

Results: Out of 400 study subjects, ZACD was found in 11 , giving an overall prevalence of $2.75 \%$. Out of 11 ZACD subjects, six were males and five were females. The mean age of subjects with ZACD was $33.9( \pm 15)$ years and a range of 18 to 65 years. The bilateral involvement of ZACD was seen in only one subject.

Conclusion: The overall prevalence of ZACD is relatively low in present study population. Knowledge of ZACD may be helpful in interpreting panoramic radiographs, in planning surgical treatment of the temporomandibular joint and in understanding the spread of pathological processes into the joint.

Keywords: Panoramic radiography, Zygomatic, Mastoid, Temporal bone.

How to cite this article: Gadda R, Patil NA, Salvi R. Zygomatic Air Cell Defect: Prevalence and Characteristics in Dental Outpatient Population. J Contemp Dent 2012;2(3):69-72.

Source of support: Nil

Conflict of interest: None declared

\section{INTRODUCTION}

Pneumatization refers to the presence or development of air-filled cavities in a bone. In addition to the major paranasal sinuses, accessory air cells may arise in numerous locations in the skull, including the temporal bone, either singly or in clusters. ${ }^{1,2}$ Tyndall and Matteson ${ }^{3}$ coined the phrase 'zygomatic air cell defect' (ZACD) specifically to describe accessory air cells which occur in the root of the zygomatic arch and in the articular eminence of the temporal bone. ${ }^{3}$

The ZACD has defined as an accessory air cells in the zygomatic process and articular eminence of the temporal bone which appears similar to the mastoid air cells and which does not extend further anteriorly than the zygomaticotemporal suture. ${ }^{3,4}$ The ZACD appears as an asymptomatic radiolucent defect in the zygomatic process of the temporal bone without enlargement or cortical destruction of the zygoma in radiographs. ${ }^{3}$
There have been case reports on ZACD in the dental literatures. ${ }^{3,5-7}$ In 1976 , Roser et al ${ }^{6}$ reported a case of pneumatization of the root of the zygomatic arch that was observed incidentally on a panoramic radiograph obtained as part of an examination of the temporomandibular joint (TMJ). Kulikowski et $\mathrm{al}^{7}$ reported the discovery of an air cells in the zygomatic arch of a patient who was undergoing surgical removal of the articular eminence for the treatment of chronic severe condylar subluxation. Tyndall and Matteson $^{3}$ re-emphasized the occurrence of ZACD and presented three cases discovered in panoramic radiographs. Several authors ${ }^{8,9}$ have suggested the importance of air cells as possible complicating factor during surgical procedure.

Panoramic radiograph is a useful technique to display the ZACD of temporal bone, since the posterior aspect of the zygomatic arch is usually displayed. ${ }^{8,9}$ Computed tomography has been used for this purpose ${ }^{10}$ but the cost makes its use difficult to justify. A few series have reported the prevalence of ZACD on panoramic radiographs in general populations. ${ }^{4,9,10}$ Tyndall and Matteson ${ }^{8}$ provided the first detailed data on prevalence and patient characteristics of pneumatized articular eminence of the temporal bone in 1985. Of a series of 1,061 panoramic radiographs, pneumatization of the articular eminence was found in 28 cases (2.6\%) with no gender predilection. Most recently, Carter et $\mathrm{al}^{4}$ described ZACD in 40 patients (1.5\%) out of 2,734 dental clinic outpatients.

The purpose of this study is to determine the prevalence, radiographic appearance and characteristics of the patients with ZACD among the dental out patient population.

\section{MATERIALS AND METHODS}

Routine panoramic radiographs of 400 patients who were visited the dental outpatient of our institute were examined retrospectively. Cases in which the zygomatic arch was not adequately displayed for anatomical or technical reasons were excluded from the sample and did not constitute part of the 400-patient sample. Subjects with developmental malformations of the face and jaws, those in whom systemic conditions had affected growth, those with clinical or radiographic evidence of pathologies in the maxillofacial region, and those with a history of trauma to the 
maxillofacial region and who had been treated with surgical intervention were excluded from the study.

Panoramic radiograph of subjects were obtained using Kodak 8000 C (Carestream Health India Pvt Ltd). Panoramic radiographs were examined by two oral and maxillofacial radiologists and consensus diagnosis was recorded (Figs $1 \mathrm{~A}$ and $\mathrm{B})$. Subjects were recorded as having ZACD only if unequivocal pneumatization of the root of zygomatic arch or articular eminence posterior to the zygomaticotemporal suture as a well-defined uni- or multilocular radiolucency could be viewed on the radiograph. The age, gender of the patients who had ZACD and its location, radiographic appearance was also recorded. The radiographic appearance was classified into two types, unilocular and multilocular. Unilocular ZACD was defined as single oval radiolucent defect with well-defined border and multilocular ZACD as numerous small radiolucent defects similar to the mastoid air cells. Also, whether ZACD is unilateral or bilateral was recorded.

\section{RESULTS}

The mean age of the 400 patients in the current study was $31.5( \pm 16.8)$ years and an overall range of 3 to 78 years.
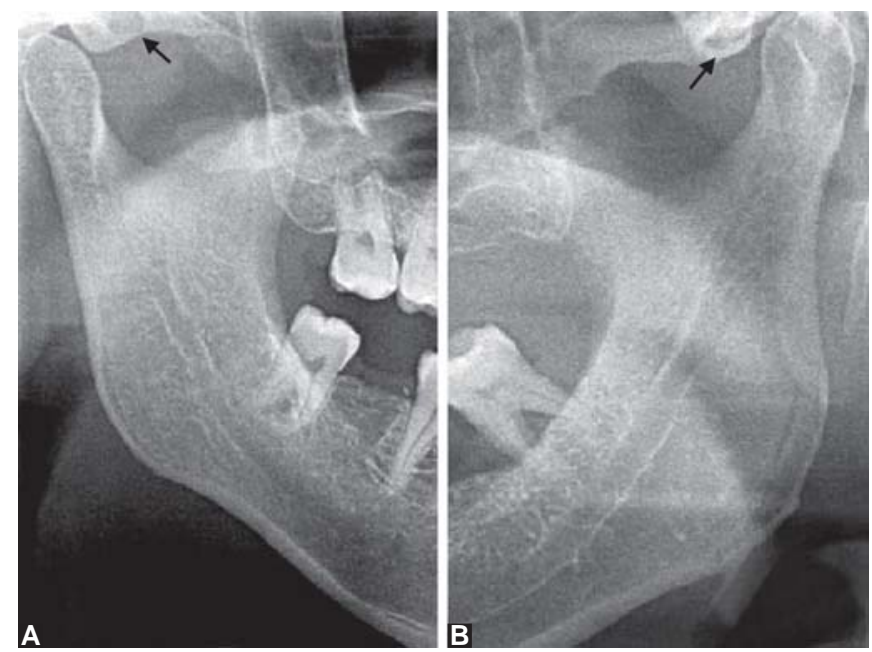

Figs $1 \mathrm{~A}$ and $\mathrm{B}$ : Cropped panoramic radiographs display typical appearance of ZACD: $(A)$ right side $(B)$ left side
There were 201 males and 199 females in the study population. The mean age of the males was $32.2( \pm 18.4)$ years and a range of 3 to 78 years, while that for the females was $30.8( \pm 15.1)$ years and a range of 5 to 76 years.

Out of 400 study subjects, ZACD was found in 11, giving an overall prevalence of $2.75 \%$. Out of 11 ZACD subjects, six were males and five were females. The mean age of subjects with ZACD was $33.9( \pm 15)$ years and a range of 18 to 65 years (Table 1 ). The bilateral involvement of ZACD was seen in only one subject. Out of unilateral cases (10), six were on right side (Table 2). All ZACD were unilocular.

\section{DISCUSSION}

The cause of ZACD is unknown but may be similar to that of pneumatization of the mastoid process. Pneumatization begins with the formation of small osseous cavities created by normal periosteal activity. ${ }^{10}$ Primitive bone marrow in these cavities dedifferentiates into a loose mesenchymal connective tissue. Epithelium invaginates into this connective tissue, producing a mucous membrane which then undergoes atrophy, leaving a thin residual lining membrane attached to the periosteum. Continued subepithelial bone resorption further expands the air cells. ${ }^{11}$

The primary regions of pneumatization of the temporal bone consist of the middle ear, squamomastoid (mastoid), perilabyrinthine, petrous apex and accessory. The accessory regions include the squamous, the zygomatico-occipital and the styloid. The tegmental or periantral air cell may extend into the zygomatic arch, producing the ZACD. ${ }^{10}$

A few series have reported the prevalence of ZACD in general populations. Tyndall and Matteson ${ }^{8}$ found 28 cases (2.6\%) of 1,061 panoramic radiographs with a mean age of 32.5 years and an age range of 15 to 74 years. No gender predilection was found and five cases were bilateral. They obtained the sample of cases from a group of mostly adult patients. Kaugars and associates ${ }^{9}$ described pneumatization in the articular eminence in eight (1\%) out of 784 panoramic radiographs reviewed. A mean age of eight cases was

\begin{tabular}{|cccc}
\hline \multicolumn{4}{c}{ Table 1: Age and gender distribution and location of ZACD } \\
\hline S. $n$ o. & Gender (male/female) & Age (years) & ZACD (unilateral/bilateral) \\
\hline 1 & Male & 45 & Bilateral \\
2 & Male & 44 & Unilateral \\
3 & Male & 60 & Unilateral \\
4 & Male & 30 & Unilateral \\
5 & Male & 26 & Unilateral \\
6 & Male & 19 & Unilateral \\
7 & Female & 31 & Unilateral \\
8 & Female & 29 & Unilateral \\
9 & Female & 19 & Unilateral \\
10 & Female & 28 & Unilateral \\
11 & Female & 18 & \\
\hline
\end{tabular}


Table 2: Involvement side in ZACD

\begin{tabular}{lcc} 
& Right & Left \\
\hline Unilateral (10) & 6 & 4 \\
Bilateral (1) & 1 & 1 \\
\hline
\end{tabular}

45.9 years with age range of 32 to 69 years. Seven patients of them were female and one was male. Four cases were unilateral and four were bilateral. Carter et $\mathrm{al}^{4}$ reported 40 cases $(1.5 \%)$ with ZACD in 2,734 dental clinic outpatients. Patients with ZACD had a mean age of 49.6 years and a range of 17 to 83 years. A total of 32 cases were unilateral and there was no gender predilection.

In the present study, ZACD was found in 11 cases (2.75\%) with a mean age of 33.9 years and an age range of 18 to 65 years. There was almost equal gender distribution (six males, five females). Ten subjects of them were unilateral ZACD. In case of unilateral involvement, six of them involved the right side. The present study revealed demonstrable similarities in the prevalence and involvement of ZACD to the previous studies. ${ }^{4,8,9}$ All of the series including this study showed low prevalence.

Two possible reasons for ZACD's being seen less often are: (1) The number of ZACD may be small as there is a wide variability in the extent of accessory air cell of temporal bone. (2) In panoramic radiograph, radiographic visualization of ZACD is more difficult because there are superimposition of adjacent anatomic structures. Highresolution computed tomography (CT) can give a better visualization in the evaluation of bony structure allowing exact delineation of temporal air spaces, ${ }^{10}$ but it is not justified because of cost and inconvenience.

In the present study, bilateral involvement of ZACD was seen in only one case. Tyndall and Matteson (17.9\%), ${ }^{8}$ Carter and his associates $(20 \%)^{4}$ demonstrated that ZACD was bilateral in approximately one-fifth of cases.

The differential diagnosis of radiolucencies within the zygomatic arch include ZACD, aneurysmal bone cyst, hemangioma, giant cell tumor, eosinophilic granuloma, fibrous dysplasia and metastatic tumor. ${ }^{12-14}$ Only the ZACD occurs in the zygomatic arch with any frequency and presents as an asymptomatic, nonexpansile, nondestructive radiolucency detected incidentally on radiograph. All of the other entities in the differential diagnosis including osseous hemangioma is a rare lesion in zygoma and would be characterized by enlarging and painful cheek, bony expansion with cortical destruction and frequently mixed density lesions. ${ }^{12-14}$

The clinical significance of ZACD is that they represent sites of minimal resistance and thus facilitate the spread of various pathologic processes into the TMJ such as tumors, inflammation or fractures and that they may be possible complicating factors during TMJ surgery. ${ }^{15}$ Inadvertent violation of an air cell during eminectomy, producing communication with the infratemporal or middle cranial fossa poses the genuine danger of intracranial infection and/ or hemorrhage. ${ }^{7}$ This points out the need for thorough preoperative imaging evaluation.

\section{CONCLUSION}

It is of utmost importance that radiologists, diagnosticians and surgeons be aware of this entity so that precise identification can be made, which not only prevents unnecessary investigations and explorations but also forewarns the surgeon and thus helps prevent potential complications.

\section{REFERENCES}

1. Tremble GE. Pneumatization of the temporal bone. Arch Otolaryngol 1934;19:172-82.

2. Srikanth HS, Patil K, Mahima VG. Zygomatic air cell defect: A panoramic radiographic study of a South Indian population. India J Radiol Imag 2010;20:112-14.

3. Tyndall DA, Matteson SR. The zygomatic air cell defect on panoramic radiographs. Oral Surg Oral Med Oral Pathol 1987; 64:373-76.

4. Carter LC, Haller AD, Calamel AD, Pfaffenbach AC. Zygomatic air cell defect (ZACD): Prevalence and characteristics in a dental clinic outpatient population. Dentomaxillofac Radiol 1999;28: 116-22.

5. Deluke DM. Pneumatization of the articular eminence of the temporal bone. Oral Surg Oral Med Oral Pathol Oral Radiol Endod 1995;79:3-4.

6. Roser SM, Rudin DE, Brady FA. Unusual bony lesion of the zygomatic arch. J Oral Med 1976;31:72-73.

7. Kulikowski BM, Schow SR, Kraut RA. Surgical management of a pneumatized articular eminence of the temporal bone. J Oral Maxillofac Surg 1982;40:311-13.

8. Tyndall DA, Matteson SR. Radiographic appearance and population distribution of the pneumatized articular eminence of the temporal bone. J Oral Maxillofac Surg 1985;43: 493-97.

9. Kaugars GE, Mercuri LG, Laskin DM. Pneumatization of the articular eminence of the temporal bone: Prevalence, development, and surgical treatment. J Am Dent Assoc 1986;113:55-57.

10. Virapongse C, Sarwar M, Bhimani S, Sasaki C, Shapiro R. Computed tomography of temporal bone pneumatization: 1 . Normal pattern and morphology. AJNR 1985;6:551-59.

11. Beaumont GD. The effects of exclusion of air from pneumatized bones. J Laryngol Otol 1966;80:236-49.

12. Eveson JW, Moos KF, MacDonald DG. Aneurysmal bone cyst of the zygomatic arch. Br J Oral Surg 1978;15:259-64.

13. Jeter TS, Hackney FL, Aufdemorte TB. Cavernous hemangioma of the zygoma: Report of cases. J Oral Maxillofac Surg 1990;48: 508-12.

14. Savastano G, Russo A, Dell’Aquila A. Osseous hemangioma of the zygoma: A case report. J Oral Maxillofac Surg 1997;55: 1352-56. 
15. Weinberg S. Eminectomy and meniscorrhaphy for internal derangements of the temporomandibular joint. Oral Surg Oral Med Oral Pathol 1984;57:241-49.

\section{ABOUT THE AUTHORS}

\section{Rohit Gadda (Corresponding Author)}

Senior Lecturer, Department of Oral Medicine and Radiology, MGM Dental College and Hospital, Navi Mumbai, Maharashtra, India e-mail: rohitgadda@gmail.com

\section{Neha Anil Patil}

Senior Lecturer, Department of Oral Medicine and Radiology MGM Dental College and Hospital, Navi Mumbai, Maharashtra India

\section{Rohini Salvi}

Professor and Head, Department of Oral Medicine and Radiology MGM Dental College and Hospital, Navi Mumbai, Maharashtra India 